\title{
Biological evaluation of porous aliphatic polyurethane/hydroxyapatite composite scaffolds for bone tissue engineering
}

Citation for published version (APA):

Yang, W., Both, S. K., Zuo, Y., Birgani, Z. T., Habibovic, P., Li, Y., Jansen, J. A., \& Yang, F. (2015).

Biological evaluation of porous aliphatic polyurethane/hydroxyapatite composite scaffolds for bone tissue engineering. Journal of Biomedical Materials Research Part A, (2014/11/06), 2251-2259. https://doi.org/10.1002/jbm.a.35365

Document status and date:

Published: 01/01/2015

DOI:

10.1002/jbm.a.35365

Document Version:

Publisher's PDF, also known as Version of record

\section{Document license:}

Taverne

Please check the document version of this publication:

- A submitted manuscript is the version of the article upon submission and before peer-review. There can be important differences between the submitted version and the official published version of record.

People interested in the research are advised to contact the author for the final version of the publication, or visit the DOI to the publisher's website.

- The final author version and the galley proof are versions of the publication after peer review.

- The final published version features the final layout of the paper including the volume, issue and page numbers.

Link to publication

\footnotetext{
General rights rights.

- You may freely distribute the URL identifying the publication in the public portal. please follow below link for the End User Agreement:

www.umlib.nl/taverne-license

Take down policy

If you believe that this document breaches copyright please contact us at:

repository@maastrichtuniversity.nl

providing details and we will investigate your claim.
}

Copyright and moral rights for the publications made accessible in the public portal are retained by the authors and/or other copyright owners and it is a condition of accessing publications that users recognise and abide by the legal requirements associated with these

- Users may download and print one copy of any publication from the public portal for the purpose of private study or research.

- You may not further distribute the material or use it for any profit-making activity or commercial gain

If the publication is distributed under the terms of Article $25 \mathrm{fa}$ of the Dutch Copyright Act, indicated by the "Taverne" license above, 


\section{Always Be Ready for What's Next with Patient Safety Net"}

Multiple studies over 10 years at Dartmouth-Hitchcock Medical Center have shown improved clinical outcomes and reduced cost of care.

\section{0}

preventable deaths or brain damage due to opioid-induced respiratory depression in monitored patients over 10 years

\section{$\downarrow 50 \%$}

approximate reduction in ICU transfers ${ }^{2}$

\section{$\downarrow 60 \%$}

approximate reduction in rapid response team activations

\section{$\downarrow 7$ Million}

Masimo SET is used to monitor over 200 million patients a year."

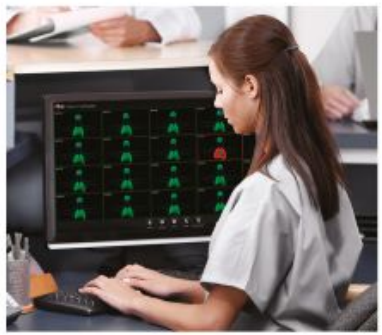

$>$ Masimo $\mathrm{SET}^{s}$ has been shown in more than 100 independent and objective studies to outperform other pulse oximetry technologies ${ }^{5}$

$>$ Radius PPG ${ }^{\text {Th }}$ tetherless pulse oximetry allows you to monitor patients from outside the room and beyond

$>$ Remote patient monitoring at central view stations

$>$ Real-time data and alarm notifications on clinicians' smartphones with Replica ${ }^{\mathrm{T}}$ 


\title{
Biological evaluation of porous aliphatic polyurethane/hydroxyapatite composite scaffolds for bone tissue engineering
}

\author{
Wanxun Yang, ${ }^{1,2}$ Sanne K. Both, ${ }^{1}$ Yi Zuo, ${ }^{3}$ Zeinab Tahmasebi Birgani, ${ }^{4}$ Pamela Habibovic, ${ }^{4}$ \\ Yubao $\mathrm{Li}^{3}{ }^{3}$ John A. Jansen, ${ }^{1}$ Fang Yang ${ }^{1}$ \\ ${ }^{1}$ Department of Biomaterials, Radboud University Medical Center, Dentistry 309, Nijmegen, The Netherlands \\ ${ }^{2}$ The State Key Laboratory Breeding Base of Basic Science of Stomatology (Hubei-MOST) and Key Laboratory of Oral \\ Biomedicine Ministry of Education, School and Hospital of Stomatology, Wuhan University, 430079 Wuhan, China \\ ${ }^{3}$ Research Center for Nano-Biomaterials, Analytical and Testing Center, Sichuan University, 610064 Chengdu, China \\ ${ }^{4}$ Department of Tissue Regeneration, MIRA Institute for Biomedical Technology and Technical Medicine, University of \\ Twente, 7500 AE Enschede, The Netherlands
}

Received 3 April 2014; revised 14 August 2014; accepted 29 October 2014

Published online 11 November 2014 in Wiley Online Library (wileyonlinelibrary.com). DOI: 10.1002/jbm.a.35365

\begin{abstract}
Biomaterial scaffolds meant to function as supporting structures to osteogenic cells play a pivotal role in bone tissue engineering. Recently, we synthesized an aliphatic polyurethane (PU) scaffold via a foaming method using nontoxic components. Through this procedure a uniform interconnected porous structure was created. Furthermore, hydroxyapatite (HA) particles were introduced into this process to increase the bioactivity of the PU matrix. To evaluate the biological performances of these PU-based scaffolds, their influence on in vitro cellular behavior and in vivo bone forming capacity of the engineered cell-scaffold constructs was investigated in this study. A simulated body fluid test demonstrated that the incorporation of $40 \mathrm{wt} \% \mathrm{HA}$ particles significantly promoted the biomineralization ability of the PU
\end{abstract}

scaffolds. Enhanced in vitro proliferation and osteogenic differentiation of the seeded mesenchymal stem cells were also observed on the PU/HA composite. Next, the cell-scaffold constructs were implanted subcutaneously in a nude mice model. After 8 weeks, a considerable amount of vascularized bone tissue with initial marrow stroma development was generated in both PU and PU/HA40 scaffold. In conclusion, the PU/HA composite is a potential scaffold for bone regeneration applications. (c) 2014 Wiley Periodicals, Inc. J Biomed Mater Res Part A: 103A: 2251-2259, 2015.

Key Words: bone regeneration, biomaterial, polyurethane, hydroxyapatite, ectopic bone formation

How to cite this article: Yang W, Both SK, Zuo Y, Birgani ZT, Habibovic P, Li Y, Jansen JA, Yang F. 2015. Biological evaluation of porous aliphatic polyurethane/hydroxyapatite composite scaffolds for bone tissue engineering. J Biomed Mater Res Part A 2015:103A:2251-2259.

\section{INTRODUCTION}

Since the concept of tissue engineering was introduced, researchers have been seeking a solution for bone repair and regeneration by combining the three key factors, that is a porous scaffold, exogenous stem cells, and biological cues. ${ }^{1}$ Essentially, the choice of a biomaterial as a scaffold is critical to the success of bone tissue engineering. ${ }^{2}$ It is widely accepted that an optimal scaffold should possess a porous and biologically compatible framework onto which bone-forming cells can attach, function, and eventually form new bone tissue. ${ }^{3}$

Recently, polyurethanes (PUs) gained popularity and have been investigated as scaffold material. A typical PU is a block copolymer consisting of a hard segment contributed by isocyanates and a soft segment formed by polyether or polyester polyols. For that reason, the material properties of PU, such as mechanical strength, biodegradability, and cytocompatibility, can be easily modified by adjusting the components of the hard and soft segments during PU synthesis. $^{4,5}$ For instance, a PU synthesized from aliphatic diisocyanate, for example isophorone diisocyanate (IPDI), non-toxic castor oil, and 1,4-butanediol (BDO) gives rise to non-toxic degradation products, which is more desirable to be used as a scaffold material than the conventional PUs made from aromatic diisocyanates. ${ }^{6,7}$ However, like most synthetic polymers, PUs lack bioactive groups to facilitate biomineralization. The most common strategy to counteract the poor bioactivity is by introducing bioactive ceramics, for example hydroxyapatite (HA) particles, into the PU matrix during the polymerization process. ${ }^{8,9}$ Due to the presence of

Correspondence to: F. Yang; e-mail: fang.yang@radboudumc.nl

Contract grant sponsor: Royal Netherlands Academy of Arts and Sciences (KNAW); contract grant number: PSA 08-PSA-M-02

Contract grant sponsor: China Scholarship Council; contract grant number: 2010627030 
polar groups in the molecular chain, PUs have relatively high affinity to HA. ${ }^{10}$

Another attractive feature of PUs is their preference to spontaneously foaming during the copolymerization process, which facilitates a one-step process of making porous scaffolds. For instance, water, which is either unavoidably present in the reaction mixture or added intentionally during the copolymerization process, reacts with the isocyanate causing the release of $\mathrm{CO}_{2}$ gas. $\mathrm{CO}_{2}$ gas creates bubbles and eventually leads to foaming. Our previous study has demonstrated that a mild foaming process could be achieved to allow the formation of a uniform porous PU structure, by carefully choosing a low reaction rate isocyanate. ${ }^{11}$ We also demonstrated that nanosized HA particles could be added into this process, resulting in the formation of a porous PU/ HA composite scaffold with good dispersion and high occupancy of HA particles. ${ }^{11,12}$

In this study, we aimed to further test the biological performance of such PU/HA scaffolds in comparison to HA free PU scaffolds, including the scaffold effect on cellular behavior and in vivo bone forming capacity of the engineered cellscaffold constructs. Firstly, the scaffolds were immersed in simulated body fluid (SBF) to test the biomineralization capacity. Furthermore, rat bone marrow derived mesenchymal stem cells (MSCs) were seeded onto the scaffolds, and the cell viability and the osteogenic capacity were tested in vitro. Finally, the efficacy of bone formation on the cellscaffold constructs was evaluated in vivo after subcutaneous implantation in nude mice.

\section{MATERIALS AND METHODS}

\section{Scaffold fabrication and morphology characterization}

All the reagents were of analytic grade and purchased from Kelong Co. (Chengdu, China), except that castor oil and IPDI were obtained from Aladdin Co. (Shanghai, China). Both castor oil and BDO were dehydrated under decompression with a vacuum of $1330 \mathrm{~Pa}$ at $120^{\circ} \mathrm{C}$. IPDI was preserved in a refrigerator before use. Nanosized HA slurry was prepared by wet synthesis as previously described ${ }^{13}$ then spray-dried to particles of $\sim 5-15 \mu \mathrm{m}$ in diameter for further experiments.

The PU and PU/HA scaffolds were prepared by copolymerization and simultaneous foaming following our previously reported method. ${ }^{11}$ The reaction was performed in a $250 \mathrm{~mL}$ three-necked round-bottom flask under a dry nitrogen atmosphere. Firstly, $38 \mathrm{~g}$ castor oil, and a certain amount of HA powders, were put into the flask and stirred uniformly. Subsequently, $11.2 \mathrm{~g}$ IPDI was added drop-wise into the $\mathrm{HA}$ /castor oil mixture and the reaction was kept for $4 \mathrm{~h}$ to form the prepolymer. Then $4.5 \mathrm{~g}$ BDO was used as a chain extender to crosslink the prepolymer and $0.9 \mathrm{~g}$ deionized water was added in the crosslinked prepolymer by stirring for $5 \mathrm{~min}$. The mixture was placed in an oven at $120^{\circ} \mathrm{C}$ for $4 \mathrm{~h}$ accompanied with simultaneous foaming, after which the three-dimensional porous bulk scaffold was obtained. Three types of scaffolds were prepared based on the amount of HA. They were named as PU, PU/HA20, and PU/HA40 with the PU:HA weight ratios of 100:0, 80:20, and
$60: 40$, respectively. For all three types of scaffolds, the overall porosity was $78-81 \%{ }^{11}$

Disk-shaped samples with a diameter of $6 \mathrm{~mm}$ and a thickness of $2.5 \mathrm{~mm}$ were punched out of the bulk scaffolds. In order to achieve further exposure of the HA particles on the surfaces, all types of scaffolds were immersed in $20 \mathrm{M}$ $\mathrm{NaOH}$ solution for 5 days under gentle agitation, as $\mathrm{NaOH}$ has the erosive effect on PU. ${ }^{14}$ After that all scaffolds were cleaned thoroughly in deionized water and freeze-dried before being used in the further experiments. The scaffold morphology was examined by scanning electron microscopy (SEM; JEOL6340F, Tokyo, Japan) after being sputter-coated with gold.

\section{Simulated body fluid immersion test}

SBF immersion test was used to evaluate the biomineralization behavior of the scaffolds. The recipe of SBF was adopted from Kokubo and Takadama ${ }^{15}$ and the $\mathrm{pH}$ value of the solution was adjusted to 7.4 after complete preparation. Immersion studies were performed by incubating each sample in $10 \mathrm{~mL} \mathrm{SBF}$ solution in a $15-\mathrm{mL}$ tube $(n=3)$. All tubes were placed in a water bath at $37^{\circ} \mathrm{C}$ under continuous shaking. After immersion periods of 1 and 4 weeks, the scaffolds were gently washed with deionized water and freeze-dried. SEM and elemental analysis of the deposits was carried out using a Philips XL30 scanning electron microscope (Eindhoven, The Netherlands) equipped with an energy dispersive spectrometer (EDS, AMETEK Materials Analysis Division, Mahwah, NJ) after the samples were sputtercoated with gold (Cressington 108A, Watford, UK). The accelerating voltage was $10 \mathrm{keV}$ and the working distance was $10 \mathrm{~mm}$. EDS analysis provided information on the distribution of elements of interest (Ca and P) in the analyzed area.

\section{Cell isolation and seeding}

Rat MSCs were isolated from 6-week-old male Wistar rats after the approval from Radboud University Nijmegen Animal Ethics Committee. Briefly, two femora of each rat were extracted and the epiphyses were cut off. MSCs were flushed out of the remaining diaphyses using the primary cell culture medium, consisting of alpha Minimal Essential Medium (aMEM; Gibco, Grand Island, USA) supplemented with $10 \%$ fetal bovine serum (FBS; Sigma, St. Louis, USA), $100 \mathrm{U} / \mathrm{mL}$ penicillin and $100 \mu \mathrm{g} / \mathrm{mL}$ streptomycin (Gibco). The flush-out was cultured for two days in a humidified incubator $\left(37^{\circ} \mathrm{C}, 5 \% \mathrm{CO}_{2}\right)$, after which the medium was refreshed to remove non-adherent cells. Prior to detaching the cells, they were cultured for an additional three days. Then, the cells were detached using trypsin/EDTA $0.25 \%$ wt/vol trypsin, 0.02\% wt/vol EDTA; Sigma) and counted.

The PU scaffolds for cell culture experiments were sterilized by autoclave and pre-wetted in primary cell culture medium overnight. For cell seeding, $5 \times 10^{4}$ cells were suspended in $50 \mu \mathrm{L}$ medium and statically seeded onto each scaffold. All scaffolds were placed in 24-well non-adherent culture plates (1 scaffold per well) and incubated for $3 \mathrm{~h}$ in a humidified incubator $\left(37^{\circ} \mathrm{C}, 5 \% \mathrm{CO}_{2}\right)$ allowing the initial 


\begin{tabular}{lll}
\hline & \multicolumn{1}{c}{ Forward $\left(5^{\prime} \rightarrow 3^{\prime}\right)$} & \multicolumn{1}{c}{ Reverse $\left(5^{\prime} \rightarrow 3^{\prime}\right)$} \\
\hline$O c$ & CGGCCCTGAGTCTGACAAA & GCCGGAGTCTGTTCACTACCTT \\
Bsp & TCCTCCTCTGAAACGGTTCC & GGAACTATCGCCGTCTCCATT \\
Run $x-2$ & GAGCACAAACATGGCTGAGA & TGGAGATGTTGCTCTGTTCG \\
Gapdh & CTTCACCACCATGGAGAAGGC & GGCATGGACTGTGGTCATGAG \\
\hline
\end{tabular}

cell attachment to the scaffolds. Subsequently, osteogenic medium was added, which contained $50 \mu \mathrm{g} / \mathrm{mL}$ ascorbic acid (Sigma), $10 \mathrm{n} M$ dexamethasone (Sigma) and $10 \mathrm{mM}$ sodium $\beta$-glycerophosphate (Sigma) on the basis of the primary culture medium. Scaffolds were maintained in culture for 24 days, with the cell culture medium being refreshed twice per week. Cell viability, DNA amount, alkaline phosphatase (ALP) activity, and osteogenic gene expression were tested.

\section{Cell viability}

LIVE/DEAD® Assay (Invitrogen) was used to assess cell viability after $24 \mathrm{~h}$ of cell seeding. The cell-scaffold constructs were washed in phosphate buffered saline (PBS) and exposed to calcein AM/ethidium homodimer-1/PBS working solution for $30 \mathrm{~min}$ at $37^{\circ} \mathrm{C}$ according to the manufacturer's instructions. Dye uptake was detected by using an automated fluorescent microscope (Axio Imager Microscope Z1; Carl Zeiss Micro Imaging $\mathrm{GmbH}$ ) with a wave length of $488 \mathrm{~nm}$ for visualizing the live cells (green) and $568 \mathrm{~nm}$ for the dead cells (red).

\section{DNA content and ALP activity}

DNA content $(n=3)$ was quantified by PicoGreen assay (Quant-iT PicoGreen dsDNA, Invitrogen) after 4, 8, 16, and 24 days of osteogenic culture condition. After the culture medium was removed, scaffolds were washed twice with PBS. Cells were harvested by placing the cell-scaffold constructs in a 1.5-mL tube. One milliliter of deionized water was added to each sample, after which two freeze-thaw cycles and ultrasonication were performed. One hundred microliters cell lysate or DNA standard from the PicoGreen assay kit was added to $100 \mu \mathrm{L}$ freshly made working solution in the wells. The results were read using a fluorescence microplate reader (Bio-Tek Instruments, Abcoude, The Netherlands) with an excitation wavelength at $485 \mathrm{~nm}$ and an emission wavelength at $530 \mathrm{~nm}$.

The ALP activity $(n=3)$ was measured as a marker for early osteogenic differentiation using the same samples as for the DNA assay. Eighty microliters of cell lysate or standard (serial dilutions of 4-nitrophenol at the concentrations of $0-25 \mathrm{n} M$ ) and $20 \mu \mathrm{L}$ of buffer solution (5 $\mathrm{mM} \mathrm{MgCl}_{2}$, 0.5M 2-amino-2-methyl-1-propanol) were added into a 96well plate. Then, $100 \mu \mathrm{L}$ of substrate solution (5 mM paranitrophenylphosphate) was added into all wells. Subsequently, the plate was incubated for $1 \mathrm{~h}$ at $37^{\circ} \mathrm{C}$ before the reaction was stopped by adding $100 \mu \mathrm{L}$ of $0.3 \mathrm{M} \mathrm{NaOH}$. The plate was read in an ELISA reader (Bio-Tek Instruments) at $405 \mathrm{~nm}$. ALP activity results were normalized by the amount of DNA.

\section{RNA extraction and real-time PCR analysis}

To analyze the expression of osteogenic-related genes of the cells seeded on each scaffold, a real-time polymerase chain reaction (PCR) was performed. Total RNA was extracted using Trizol ${ }^{\circledR}$ method (Invitrogen) after 4 and 8 days of culturing. Briefly, scaffolds with cells were washed with PBS before $1 \mathrm{~mL}$ of Trizol ${ }^{\circledR}$ solution was added. The cell extract was then collected, mixed with chloroform, and centrifuged. Only the upper aqueous phase was collected and mixed with equal amount of isopropanol. After $10 \mathrm{~min}$ of incubation at room temperature, the extract was centrifuged and washed twice with $75 \%$ alcohol. The RNA pellet was dissolved in RNA free water and the total RNA concentration was measured with spectrophotometer (NanoDrop 2000, Thermal scientific, Wilmington, USA).

First strand cDNA was reverse transcribed from RNA using the SuperScript First-Strand Synthesis System kit (Invitrogen). Afterwards cDNA was further amplified and the expression of specific genes was quantified using IQ SYBR Green Supermix PCR kit (BioRad, Hemel Hempstead, United Kingdom) in a real-time PCR (BioRaD, CFX96 ${ }^{\mathrm{TM}}$ real-time system). Osteogenic markers expressed on RNA level were evaluated, including osteocalcin $(O c)$, bone sialoprotein $(B s p)$, and runt-related transcription factor 2 (Runx2) (Table I). The expression levels were analyzed and compared to the housekeeping gene glyceraldehyde-3phosphate dehydrogenase (Gapdh). The specificity of the primers was tested separately before the real-time PCR reaction. The expression of the tested genes was calculated via the $2^{-\Delta \Delta \mathrm{Ct}}$ method $^{15}$ and the PU scaffolds were used as the reference group.

\section{In vivo implantation}

Based on the in vitro results, two types of scaffolds, PU and PU/HA40 with distinct biological properties were sterilized by autoclave and selected for the in vivo study. The protocol was approved by the Animal Ethical Committee of the Radboud University Nijmegen Medical Centre (Approval no: RU-DEC 2010-254) and the national guidelines for the care and use of laboratory animals were applied. Before in vivo implantation, 250,000 cells were seeded on each scaffold and cultured for 5 days in vitro. Afterwards, the cell-scaffold constructs were implanted subcutaneously in three male nude mice (HsdCpb:NMRInu, Harlan). Surgery was performed under general inhalation anesthesia with a combination of isoflurane, nitrous oxide, and oxygen. All mice received analgesic before and after the surgery. The back of the mice was shaved and disinfected with povidone-iodine. Subsequently, four small 


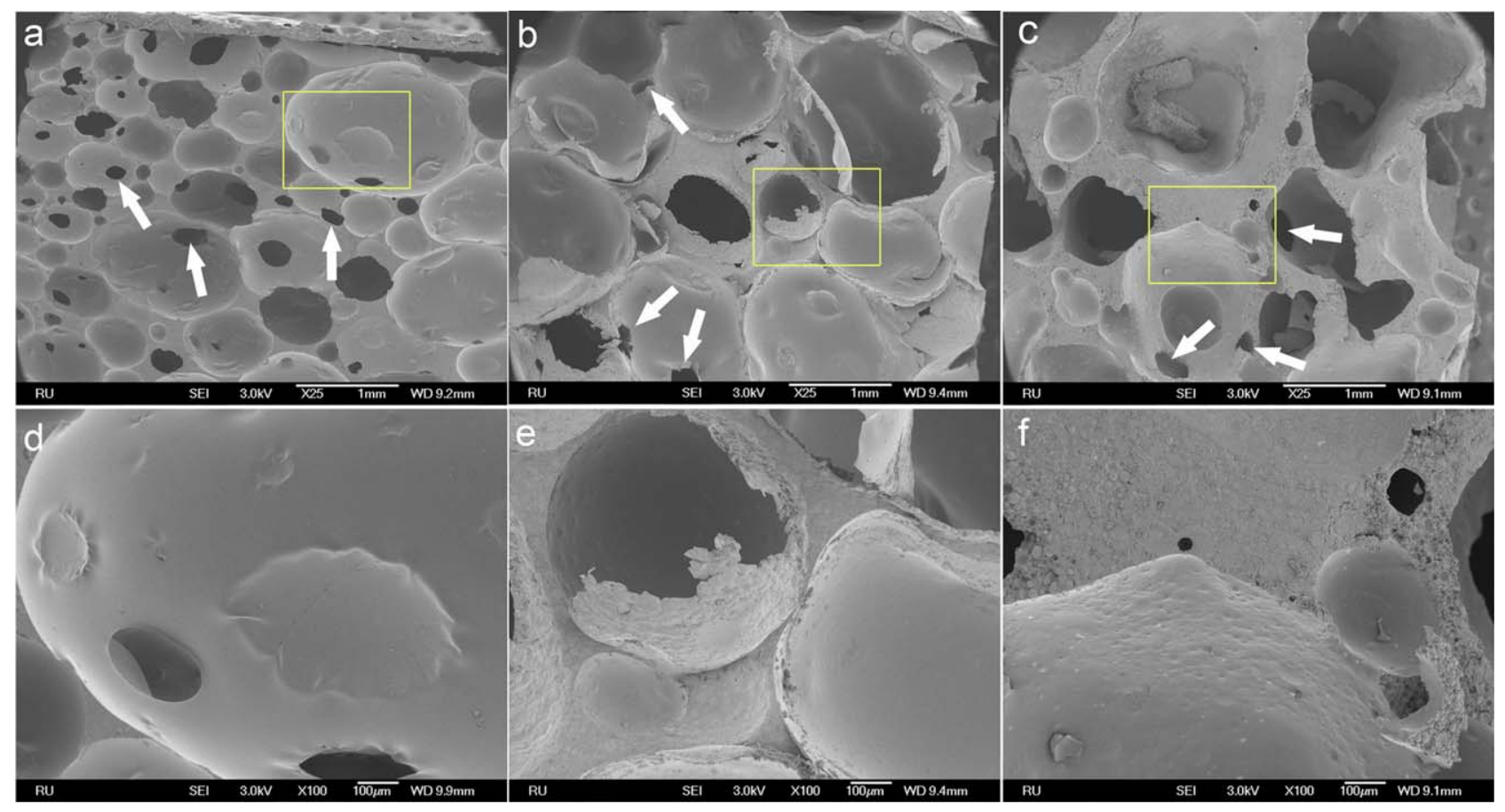

FIGURE 1. SEM micrographs of the PU (a, d), PU/HA20 (b, e), and PU/HA40 (c, f) scaffolds. The PU and PU/HA scaffolds displayed a porous structure. PU/HA20 and PU/HA40 scaffolds exhibited a less regular pore shape compared to PU scaffolds (a-c). In the magnified figures (d-f), an increased unevenness on pore surfaces of PU/HA20 and PU/HA40 was observed. (White arrow indicates the interconnection of pores.) [Color figure can be viewed in the online issue, which is available at wileyonlinelibrary.com.]

longitudinal incisions were made. Lateral to each incision, a subcutaneous pocket was created. A cell-scaffold construct and a cell-free scaffold from both PU and PU/HA40 groups were implanted in each mouse. Afterwards the skin was closed using staples. After 8 weeks, the mice were euthanized by $\mathrm{CO}_{2}$-suffocation for sample collection.

\section{Histological analysis}

After retrieval, all the in vivo samples were fixed in $10 \%$ phosphate buffered formalin for $30 \mathrm{~h}$ and dehydrated through graded ethanol before embedding in methylmethacrylate (MMA, L.T.I., Bilthoven, The Netherlands). Embedded samples were sectioned perpendicularly to the circular plane of the samples using a microtome equipped with diamond blade (Leica SP1600, Leica microsystem, Wetzlar, Germany). The sections were stained with methylene blue and basic fuchsin ${ }^{16}$ (both reagents from Merck), and imaged using a light microscope (Zeiss Imager Z1, Carl Zeiss AG Microscopy, Germany) equipped with AxioCam MRc5 camera. Three sections from the middle third of each specimen were used for histological evaluation.

\section{Statistic analysis}

Statistical significance in this study was evaluated using ANOVA analysis followed by Tukey's Multiple Comparison Test (GraphPad Software Inc., San Diego, USA). Results are reported as mean values and standard deviation.
Differences were considered statistically significant at $p<0.05$.

\section{RESULTS \\ Scaffold morphology}

As shown in the SEM micrographs (Fig. 1), the PU and PU/ HA scaffolds displayed a porous structure with the pore size ranging from 300 to $1000 \mu \mathrm{m}$. The pore walls were interconnected by the small pores with the diameter ranging from 50 to $300 \mu \mathrm{m}$ [Fig. 1(a-c)]. Compared to PU scaffolds, PU/HA20 and PU/HA40 scaffolds exhibited a less regular shape of the pores and an unevenness of the pore wall topography due to the presence of the HA particles [Fig. $1(d-f)]$.

\section{Biomineralization test}

After 1-week immersion in SBF solution, no obvious calcium phosphate (CaP) precipitation was observed on either PU or PU/HA20 scaffolds by SEM, whereas EDS detected marginal quantities of calcium and phosphorus [Fig. 2(a-d)]. In comparison, a significant extent of coverage by flake-like crystal structure was observed on the surfaces of the PU/HA40 scaffold [Fig. 2(f)]. The EDS detected considerable amount of calcium and phosphorus from these deposits, which confirmed the formation of CaP [Fig. 2(e)]. These flake-like CaP depositions formed a dense multi-layer crystal structure when the immersion period reached 4 weeks [Fig. 3(f)]. EDS also confirmed a more pronounced signal of calcium 


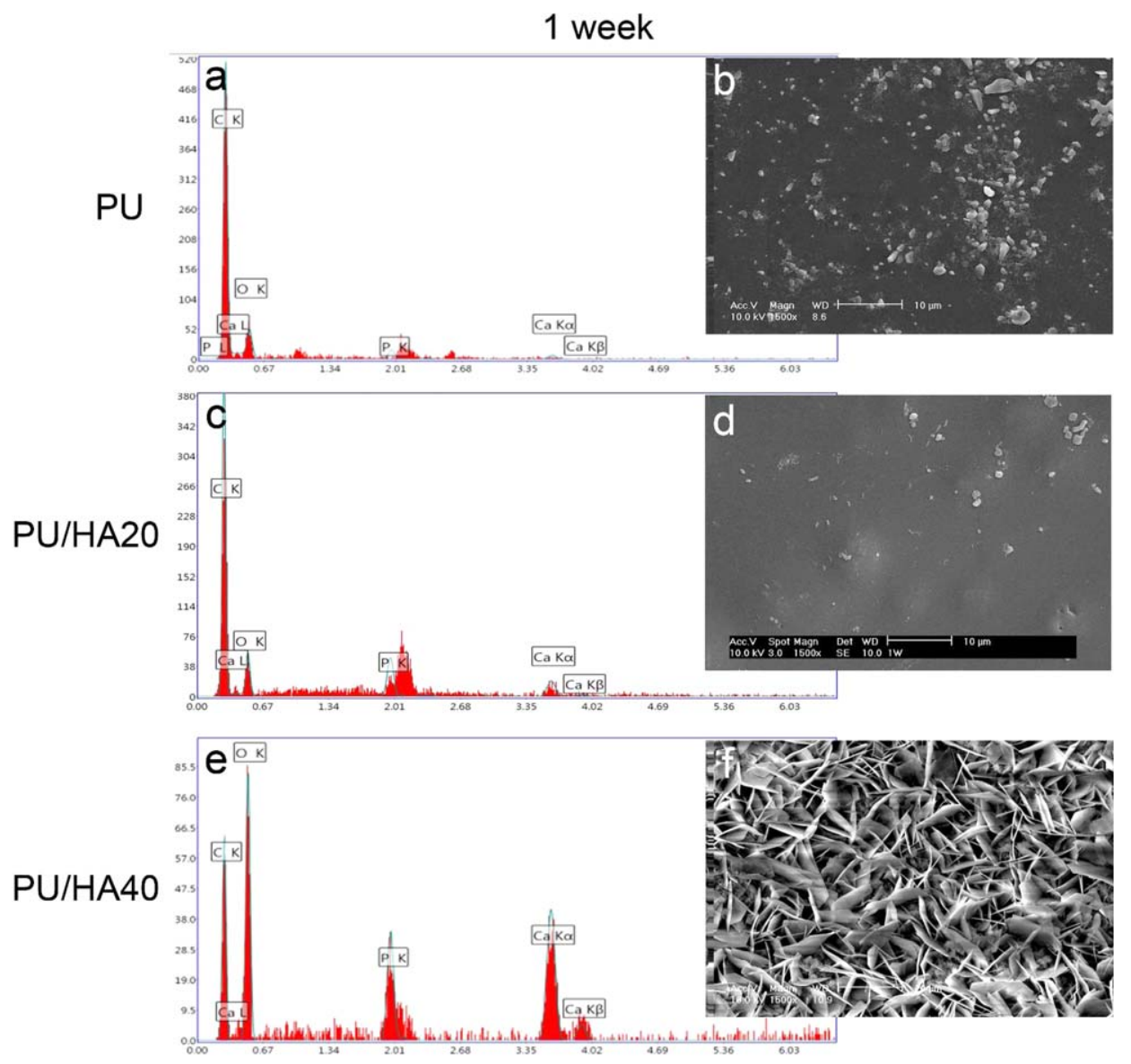

FIGURE 2. Biomineralization of the scaffolds after 1-week immersion in SBF. EDS detected marginal quantities of calcium and phosphorus on PU (a) and PU/HA20 (c) scaffolds, while no obvious CaP precipitation was observed on these scaffolds by SEM (b, d). In comparison, significant coverage by flake-like crystal structure was observed on the PU/HA40 scaffold (f), from which a considerable amount of calcium and phosphorus were detected by EDS (e). [Color figure can be viewed in the online issue, which is available at wileyonlinelibrary.com.]

and phosphorus on the PU/HA40 scaffolds [Fig. 3(e)]. By contrast, only limited CaP crystal deposition was observed to scatter on the surface of PU and PU/HA20 scaffolds after 4 weeks [Fig. 3(a-d)].

\section{Cell viability and proliferation}

As assessed by the Live/Dead assay, more than $95 \%$ of the cells were viable on all experimental scaffolds after $24 \mathrm{~h}$ of cell seeding (Fig. 4). Furthermore, the DNA contents [Fig. 5(a)], associated with the cell numbers, increased gradually until day 8 for all groups. On day 16, a decreased DNA content was detected on all groups compared to that on day 8, while the amount maintained stable thereafter. At all time points, the PU/HA20 and PU/HA40 groups displayed a significantly enhanced DNA content compared to the PU group. From day 16 onwards, a higher DNA content was also found on group PU/HA40 compared to PU/HA20.

\section{Osteogenic differentiation}

The expression of ALP activity was measured as a marker of osteogenic differentiation of the cells [Fig. 5(b)]. Higher ALP activity was found on the PU scaffolds compared to PU/HA composite in the early stage of cell culture until day
8. However, the PU/HA40 scaffolds exhibited considerably higher ALP activity compared to that on PU scaffolds at day 16 and day 24. On RNA level, the PCR results also revealed that the PU/HA composites, compared to the PU scaffold, promoted the expression of Bsp and Runx2 at day 4 [Fig. 6(a)], and the expression of Oc at day 8 [Fig. 6(b)].

\section{In vivo evaluation}

All animals remained in good health and no signs of wound complications were observed postoperatively. After 8 weeks, all implanted scaffolds were retrieved. Neither macroscopic signs of inflammation nor adverse tissue responses were discerned. Histological observation showed that all scaffolds (with or without cell seeded) were encapsulated by a thin fibrous layer (3-6 layers of fibroblasts) without significant inflammatory cells infiltration (Fig. 7). Inside of the fibrous capsule, new bone formation (stained red) was observed in all cell-scaffold constructs for both PU and PU/HA40 groups, which was present not only at the periphery of the scaffolds [Fig. $7(\mathrm{a}, \mathrm{b})]$, but also penetrated in the core areas (Fig. 8). By contrast, the implanted cell-free PU/HA scaffolds only exhibited fibrous capsulation without any bone formation 

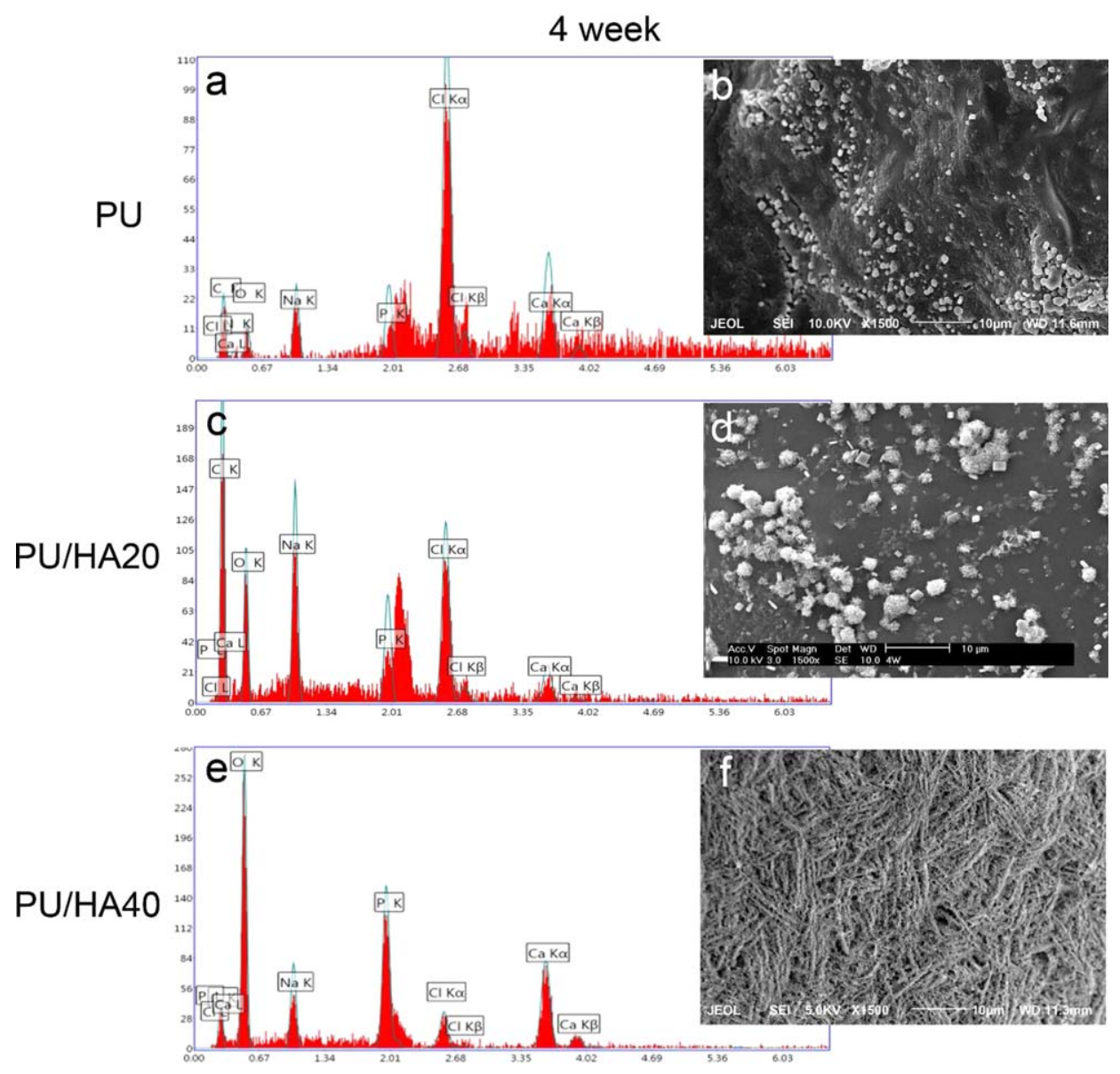

FIGURE 3. Biomineralization of the scaffolds after 4-week immersion in SBF. A limited CaP crystal deposit was shown on the surfaces of PU (a, b) and PU/HA20 (c, d) scaffolds, while a dense multilayer crystal structure with pronounced calcium and phosphorus composition was detected on the PU/HA40 scaffolds $(e, f)$. [Color figure can be viewed in the online issue, which is available at wileyonlinelibrary.com.]

[Fig. 7(c)]. Due to the deformation of the scaffolds during histological processing and the transparency of the PU scaffolds after being embedded in MMA, quantification of the bone volume on the scaffolds could not be performed to determine which group had higher amount of bone formation. Nevertheless, similar bone quality was observed on the PU and PU/HA40 scaffolds from the histological evaluation. As shown in Figure $8(a, b)$, lamellar-like bone tissue was observed inside of the pores and mainly aligned along the pore surface. The central area displayed a bone marrow structure, which was filled with a great number of hematopoietic cells (stained dark blue) and adipocytes (with bubble-like morphology) [Fig. 8(c,d)]. Meanwhile, an immature woven bone-like structure was also found in some pores, which showed the onset of bony matrix deposition with randomly arranged osteocytes.
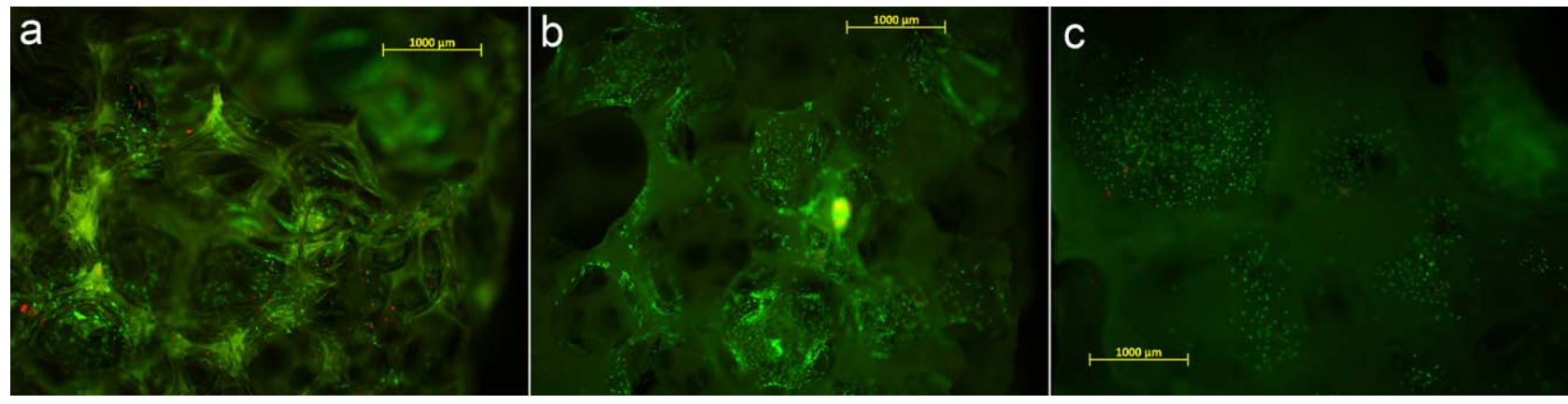

FIGURE 4. Cell viability on PU (a), PU/HA20 (b), and PU/HA40 (c) scaffolds. More than $95 \%$ of the cells were viable on all experimental scaffolds after $24 \mathrm{~h}$ of cell seeding. (Live cells are stained green and dead cells are stained red.) [Color figure can be viewed in the online issue, which is available at wileyonlinelibrary.com.] 
a

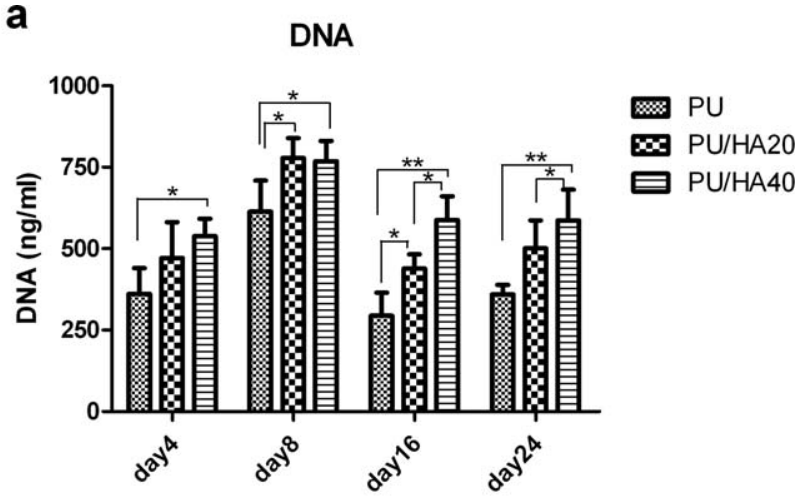

b

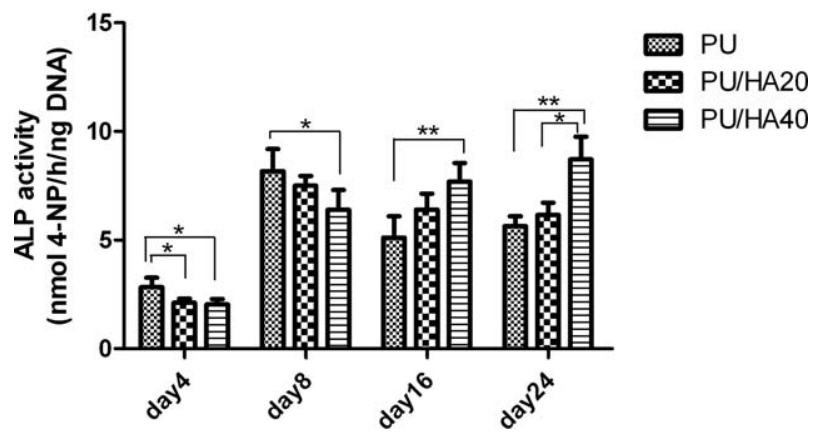

FIGURE 5. DNA contents (a) and ALP activity (b) on PU, PU/HA20, and $\mathrm{PU} / \mathrm{HA} 40$ scaffolds. ${ }^{*} p<0.05,{ }^{*} p<0.01$; error bars represent standard deviation $(n=3)$.

Osteoblasts were observed to align on the periphery of the newly formed bone matrix [Fig. 8(d)].

\section{DISCUSSION}

In the current study, aliphatic PU scaffolds incorporated with different amounts of HA particles were synthesized by in situ polymerization and simultaneous foaming method, subsequently their biological performance for bone tissue engineering applications was evaluated.

Biomineralization of the PU and PU/HA scaffolds, which is related to bone-bonding capacity, was evaluated by examining the apatite formation ability on the scaffold surfaces by incubating the scaffolds in SBF with ion concentrations equal to human blood plasma. ${ }^{15}$ Our results indicated that the incorporation of $40 \%$ HA particles significantly enhanced the biomineralization ability of the PU scaffolds. This might be attributed to the partial dissolution of HA and the subsequent release of calcium ions from PU/HA40 scaffolds, which was more sufficient to favor CaP deposition compared to that from the PU or PU/HA20 scaffolds. Additionally, the exposure of HA particles on the surface of PU/ HA40 provided more nucleation sites for CaP formation and growth. ${ }^{17}$

Biocompatibility is a primary feature of scaffold materials for tissue engineering applications. Recently, Williams has reevaluated the definition of biocompatibility and pointed out that biocompatibility of a scaffold should not be solely dependent on not eliciting any undesirable effects on the cells or the host as an insertable material. ${ }^{18}$ More importantly, the scaffolds should also support the appropriate cellular activity to optimize tissue regeneration. ${ }^{18}$ Our results showed that both PU and PU/HA scaffolds maintained the viability and supported progressive growth of the seeded cells in vitro. Notably, loading HA particles into the PU matrix improved the proliferation of the cells. The enhanced cell growth on the PU/HA composite might be closely related to the HA particles which increased the initial anchoring and spreading of serum proteins on the polymer surfaces. ${ }^{19}$ Moreover, the addition of HA could increase surface oxygen, ${ }^{20}$ which has been shown to improve the attachment and proliferation of osteoblast-like cells on biomaterials. ${ }^{21}$

An enhanced osteogenic differentiation of the seeded cells has also been demonstrated with the PU/HA scaffolds by the increase of ALP activity and up-regulation of the osteogenic-related genes. The up-regulated genes were Bsp and Runx2, which are important for orienting osteoprogenitors toward the osteo-lineage and regulating the initial stages of crystal growth, ${ }^{22}$ and $O c$, which is closely related to the late mineralization process. Addition of HA promoting osteogenic differentiation of the cells is probably attributed to two reasons: (1) the increased roughness of the PU/HA scaffolds and (2) the release of calcium and phosphate from the PU/HA scaffolds into cell culture medium or the microenvironment of the seeded cells. Previous studies have shown that an increased roughness in three-dimensional scaffolds resulted in an enhanced osteogenic differentiation. ${ }^{23}$ However, such topography is expected to have a limited impact when a highly porous and interconnected scaffold is applied, as it will only be effective for the cells directly attached on the rough surface but not those present
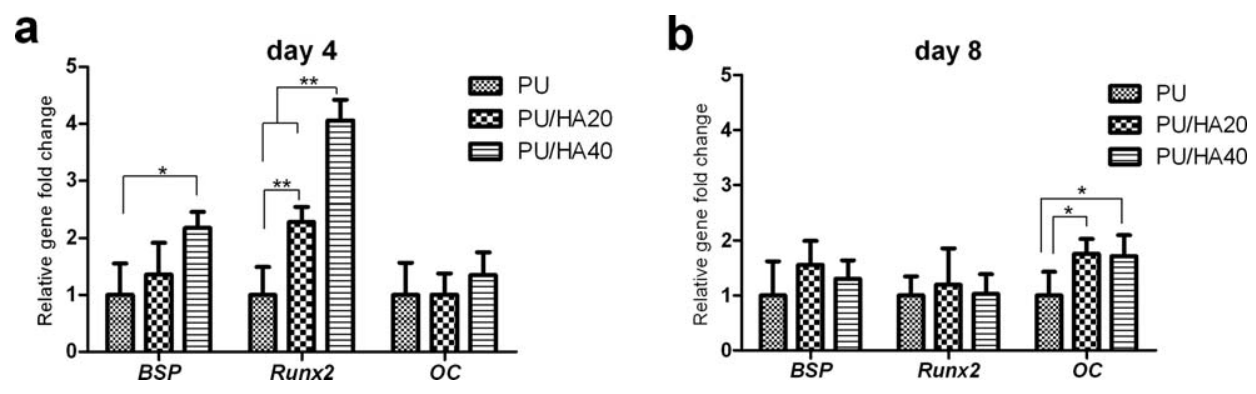

FIGURE 6. Expression of osteogenic related genes. Compared to PU, the PU/HA scaffolds promoted the expression of Bsp and Runx2 at day 4 (a), and $O c$ at day 8 (b). ${ }^{*} p<0.05,{ }^{*} p<0.01$; error bars represent standard deviation $(n=4)$. 

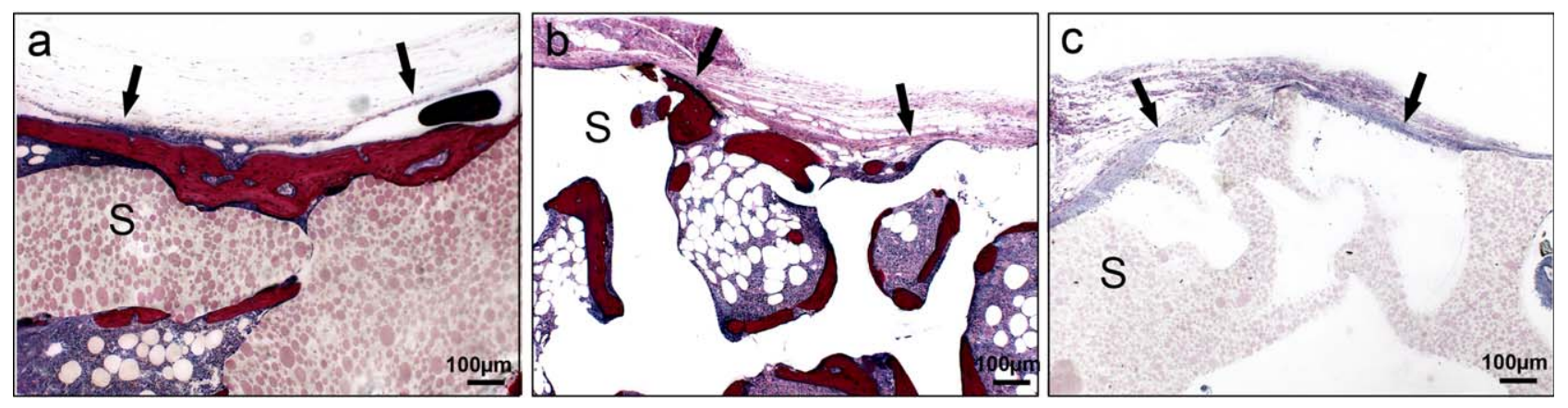

FIGURE 7. Capsulation and bone formation on the periphery of the scaffolds after in vivo implantation. All implanted scaffolds (with or without cell seeded) were encapsulated by a thin fibrous layer without significant inflammatory infiltration. Inside of the fibrous capsule new bone formation (stained red) was observed in cell-scaffold constructs for both PU/HA40 (a) and PU (b) groups, but not in the cell-free PU/HA scaffolds (c). (S: scaffolds; black arrow: fibrous capsule). [Color figure can be viewed in the online issue, which is available at wileyonlinelibrary.com.]

in the pores. ${ }^{24}$ Thus, we speculate that the calcium and phosphate release from HA represents a more effective differentiation signal. Our data is consistent with other studies, which showed that HA provides a favorable environment for osteoblast-like cell differentiation. ${ }^{25,26}$

The engineered cell-scaffold constructs were further implanted subcutaneously to gain insight in their role to support osteogenic differentiation of the cells after transplantation. The reason to choose an ectopic model instead of an orthotopic model for this study was to eliminate or reduce the number of variables involved in bone formation present in a bony environment, for instance bone stimulating cytokines, endogenous progenitor/stem cells, and potentially bone-stimulating mechanotransduction. ${ }^{27}$ Our result indicated that the PU and PU/HA40 scaffolds supported the cellular growth in vivo. Furthermore, the cell-scaffold constructs worked as an osteoinductive complex and were capable of

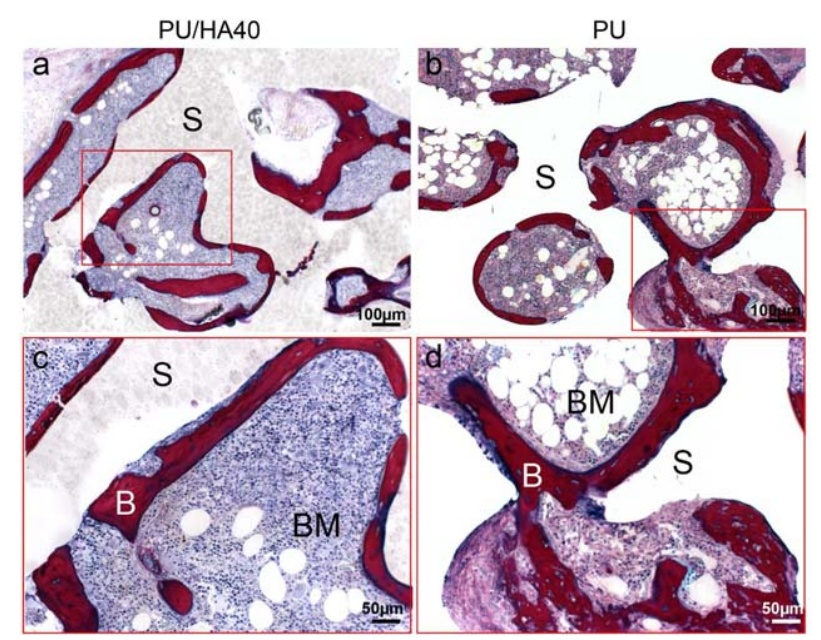

FIGURE 8. Bone in-growth to the scaffolds after in vivo implantation. On both PU/HA40 (a, c) and PU (b, d) constructs with cell seeded, lamellar-like bone tissue was observed in the core area of the scaffolds, mainly aligning along the pore surface. Surrounded by the bone matrix, a large number of hematopoietic cells and adipocytes (with bubble-like morphology) were observed, which displayed a bone marrow structure. (B: bone; BM: bone marrow; S: scaffold). [Color figure can be viewed in the online issue, which is available at wileyonlinelibrary.com.] generating new bone tissue. After 8 weeks of implantation, the bone was still in an active forming and remodeling phase.

Due to the sample deformation during the histological processing, the in vivo degradation of both $\mathrm{PU}$ and PU/HA samples could not be quantified in this study. In theory, the PU matrix can undergo degradation through the hydrolysis of ester linkages which were introduced by castor oil. ${ }^{4}$ The breakdown of these ester bonds yields hydroxyl and carboxylic groups. ${ }^{7}$ The acidic carboxyl group accelerates further hydrolysis and the degradation becomes autocatalytic. ${ }^{6}$ Previous results demonstrated an approximate $10 \%$ weight loss of aliphatic PU/HA40 scaffolds after being soaked in PBS for 8 weeks in vitro. ${ }^{12}$ Additionally, it is expected that the PU matrix would undergo a faster degradation in vivo as the presence of inflammatory cells would also contribute to this process. ${ }^{28}$ As an ideal scaffold should possess a degradation profile which matches the rate of neotissue formation, ${ }^{29}$ further investigations are necessary to evaluate the degradation of PU/HA scaffolds in an orthotopic location and monitor their replacement by the tissue in-growth.

Although the PU/HA40 scaffolds showed higher biomineralization ability and significant enhancement of osteoblastic differentiation of the seeded cells in vitro compared to the PU scaffolds, similar quality of the ectopic bone formation was revealed on these two scaffolds after 8 weeks in vivo. Previous studies have also shown a lack of correlation and predictability of in vitro osteogenic marker expression on subsequent in vivo ectopic bone formation. ${ }^{24,30}$ One possible reason might be that, the release of calcium and phosphate from PU/HA40 was not sufficient to influence the cellular behavior and local ionic concentration to trigger more bone formation or faster bone maturation once implanted. On the other hand, it should be noted that the ectopic bone formation occurred in an intradermal environment, which lacks naturally bone-forming stem cells and stimulators. ${ }^{27}$ Such an environment differs from the condition used for in vitro cell culture where the osteogenic growth factors and supplements are sufficiently supplied. Therefore, it is expected that the PU/HA40 scaffolds will probably show superior behavior in promoting the osteoblastic differentiation of osteoprogenitors and/or stem cells 
when applied in orthotopic locations. Our study warrants further investigation toward a clinical implementation of the PU/HA scaffolds, including (1) scaling up of the implanted constructs and (2) orthotopic implantation in an immunocompetent animal model in which endogenous stem cells, mechanical load, and biochemical/inflammatory factors are closely involved in the bone forming process.

\section{CONCLUSIONS}

Porous aliphatic PU and PU/HA composite scaffolds were synthesized by a foaming method and their biological performances were evaluated in this study. The incorporation of $40 \mathrm{wt}$ $\%$ HA nanoparticles into PU significantly promoted the biomineralization ability of the scaffolds and enhanced the in vitro proliferation and osteogenic differentiation of the seeded MSCs. In vivo implantation revealed that a considerable amount of vascularized bone tissue with marrow stroma development was generated on both PU and PU/HA40 scaffold after 8 weeks. Overall, with improved mechanical strength and efficacy of supporting osteogenesis, the PU/HA composite is a potential scaffold for bone regeneration applications.

\section{REFERENCES}

1. Langer R, Vacanti JP. Tissue engineering. Science 1993;260: 920-926.

2. Lee J, Cuddihy MJ, Kotov NA. Three-dimensional cell culture matrices: State of the art. Tissue Eng Part B Rev 2008;14:61-86.

3. Hutmacher DW, Schantz JT, Lam CX, Tan KC, Lim TC. State of the art and future directions of scaffold-based bone engineering from a biomaterials perspective. J Tissue Eng Regen Med 2007;1: 245-260.

4. Guelcher SA. Biodegradable polyurethanes: Synthesis and applications in regenerative medicine. Tissue Eng Part B Rev 2008;14: 3-17.

5. Santerre JP, Woodhouse K, Laroche G, Labow RS. Understanding the biodegradation of polyurethanes: From classical implants to tissue engineering materials. Biomaterials 2005;26:7457-7470.

6. Gorna K, Gogolewski S. Preparation, degradation, and calcification of biodegradable polyurethane foams for bone graft substitutes. J Biomed Mater Res A 2003;67:813-827.

7. Kavlock KD, Pechar TW, Hollinger JO, Guelcher SA, Goldstein AS. Synthesis and characterization of segmented poly(esterurethane urea) elastomers for bone tissue engineering. Acta Biomater 2007;3:475-484.

8. Rezwan K, Chen QZ, Blaker JJ, Boccaccini AR. Biodegradable and bioactive porous polymer/inorganic composite scaffolds for bone tissue engineering. Biomaterials 2006;27:3413-3431.

9. Huang $M$, Wang $Y$, Luo $Y$. Biodegradable and bioactive porous polyurethanes scaffolds for bone tissue engineering. J Biomed Sci Eng 2009;2:36-40.

10. Wei J, Li Y. Tissue engineering scaffold material of nano-apatite crystals and polyamide composite. Eur Polym J 2004;40:509-515.

11. Wang L, Li Y, Zuo Y, Zhang L, Zou Q, Cheng L, Jiang H. Porous bioactive scaffold of aliphatic polyurethane and hydroxyapatite for tissue regeneration. Biomed Mater 2009;4:025003.
12. Liu $H$, Zhang $L$, Zuo $Y$, Wang $L$, Huang $D$, Shen J, Shi $P$, Li $Y$. Preparation and characterization of aliphatic polyurethane and hydroxyapatite composite scaffold. J Appl Polym Sci 2009; 112(Compendex):2968-2975.

13. Correia RN, Magalhaes MCF, Marques PAAP, Senos AMR. Wet synthesis and characterization of modified hydroxyapatite powders. J Mater Sci Mater Med 1996;7(Compendex):501-505.

14. Schweitzer PA. Corrosion Resistance Tables: Metals, Nonmetals, Coatings, Mortars, Plastics, Elastomers and Linings, and Fabrics. Cleveland, Ohio: CRC Press; 2004. 3496 p.

15. Kokubo T, Takadama H. How useful is SBF in predicting in vivo bone bioactivity? Biomaterials 2006;27:2907-2915.

16. van der Lubbe HB, Klein $\mathrm{CP}$, de Groot $\mathrm{K}$. A simple method for preparing thin (10 microM) histological sections of undecalcified plastic embedded bone with implants. Stain Technol 1988;63:171-176.

17. Yang F, Both SK, Yang X, Walboomers XF, Jansen JA. Development of an electrospun nano-apatite/PCL composite membrane for GTR/GBR application. Acta Biomater 2009;5:3295-304.

18. Williams DF. On the mechanisms of biocompatibility. Biomaterials 2008;29:2941-2953.

19. Bonzani IC, Adhikari R, Houshyar S, Mayadunne R, Gunatillake P, Stevens MM. Synthesis of two-component injectable polyurethanes for bone tissue engineering. Biomaterials 2007;28:423-433.

20. Laschke MW, Strohe A, Menger MD, Alini M, Eglin D. In vitro and in vivo evaluation of a novel nanosize hydroxyapatite particles/ poly(ester-urethane) composite scaffold for bone tissue engineering. Acta Biomater 2010;6:2020-2027.

21. Poulsson $A H$, Mitchell SA, Davidson MR, Johnstone AJ, Emmison $\mathrm{N}$, Bradley $\mathrm{RH}$. Attachment of human primary osteoblast cells to modified polyethylene surfaces. Langmuir 2009;25:3718-3727.

22. Seyedjafari E, Soleimani M, Ghaemi N, Shabani I. Nanohydroxyapatite-coated electrospun poly(L-lactide) nanofibers enhance osteogenic differentiation of stem cells and induce ectopic bone formation. Biomacromolecules 2010;11:3118-3125.

23. Vlacic-Zischke J, Hamlet SM, Friis T, Tonetti MS, Ivanovski S. The influence of surface microroughness and hydrophilicity of titanium on the up-regulation of TGFbeta/BMP signalling in osteoblasts. Biomaterials 2011;32:665-671.

24. Vaquette C, Ivanovski S, Hamlet SM, Hutmacher DW. Effect of culture conditions and calcium phosphate coating on ectopic bone formation. Biomaterials 2013;34:5538-5551.

25. Kim K, Dean D, Lu A, Mikos AG, Fisher JP. Early osteogenic signal expression of rat bone marrow stromal cells is influenced by both hydroxyapatite nanoparticle content and initial cell seeding density in biodegradable nanocomposite scaffolds. Acta Biomater 2011;7:1249-1264.

26. Ozawa S, Kasugai S. Evaluation of implant materials (hydroxyapatite, glass-ceramics, titanium) in rat bone marrow stromal cell culture. Biomaterials 1996;17:23-29.

27. Scott MA, Levi B, Askarinam A, Nguyen A, Rackohn T, Ting $K$, Soo C, James AW. Brief review of models of ectopic bone formation. Stem Cells Dev 2012;21:655-667.

28. Anderson JM, Rodriguez A, Chang DT. Foreign body reaction to biomaterials. Semin Immunol 2008;20:86-100.

29. Hutmacher DW. Scaffolds in tissue engineering bone and cartilage. Biomaterials 2000;21:2529-2543.

30. Chai YC, Roberts SJ, Desmet E, Kerckhofs G, van Gastel N, Geris L, Carmeliet G, Schrooten J, Luyten FP. Mechanisms of ectopic bone formation by human osteoprogenitor cells on CaP biomaterial carriers. Biomaterials 2012;33:3127-3142. 